\title{
The protection of urban areas from surface wastewater pollutions
}

\author{
Elena Vialkova ${ }^{1, *}$, Marina Zemlyanova ${ }^{1}$, Anna Vorotnikova $^{1}$, Dmitriy Cherkashin ${ }^{1}$, Andrey \\ Voronov $^{1}$, Lev Maksimov ${ }^{1}$ \\ ${ }^{1}$ Tyumen Industrial University, Volodarskogo str., 38, Tyumen, 625000, Russia
}

\begin{abstract}
In this paper it considered the problem of collection, treatment and discharge into waters of rain and melted wastewater. To reduce the load on the combined sewer system, there are engineering solutions collect rain and melt water for use in the irrigation of lawns and green spaces. Research carried out at the department "Water supply and sanitation", (Russia), confirm the high pollution concentrations of meltwater and rainfall in urban arias. Series of measurements of heavy metal in rainwater runoff carried out in Hungary demonstrates clearly the differences in concentrations in the function of distance from the edge of the road. Also differences are introduced between pollution concentrations in runoff water from within and outside urban traffic roads. The quality of snow cover, forming meltwater is observed to be changing in dependence on roadway location. Quality characteristics of surface runoff and its sediments can be effectively improved with super-high frequency radiation (SHF) treatment which is presented in this paper.
\end{abstract}

\section{Introduction}

Studying the problem of urban environment becomes now more and more important. The population of economically developed areas are concentrated in the cities, where the bulk of industrial enterprises can be found.

The sanitary condition of the residential areas is determined by several factors, the most important of which is the timely collection and removal of irrigation, rainwater and meltwater.

Quantitative and qualitative composition of runoff depends on the time of year, the quantity and quality of precipitation, as well as landscaping, the intensity of vehicular traffic, the availability and condition of rainwater drainage systems. One of the problems of quantifying runoff is a huge irregularity depending on the intensity of rainfall and the formation of water during periods of active snowmelt. To reduce the load of the combined sewer system, there exist engineering solutions for the collection and storing of these water volumes for further usage as irrigation water or groundwater recharge through infiltration techniques.

\footnotetext{
${ }^{*}$ Corresponding author: vyalkova-e@yandex.ru
} 


\section{Review}

When the quality of surface runoff is being determined, it is necessary to take local anthropogenic sources of pollution into account. The chemical substances entering the environment in the course of production and domestic activities of the urban population are extremely diverse. The pollution participates in the migration and will eventually have a negative impact on human health. Pollution of urban runoff consists mainly of heavy metals, oil products, phenols and nitrogen compounds. On the basis of the laboratory of the department "Water supply and sanitation", the Tyumen Industrial University (Tyumen, Russia) carried out a research with the aim to study the quality indicators of polluted runoff water, soil and snow that covers the city. Historically, the treatment of polluted runoff water has got only little attention. It is believed that the concentration of pollutants in rain water is high only in the first twenty minutes of rainfall, so they do not harm the environment. Often, the storm wastewater is moved directly into the reservoir without purification. Indeed, the concentration of pollution is not very high in these waters, but it is strongly dependent on the area of construction (composition of the soil and other geological conditions), city improvement and season. Thawing water is characterized by a very high content of suspended matters - from $2000 \mathrm{mg} / \mathrm{dm}^{3}$ to $600 \mathrm{mg} / \mathrm{dm}^{3}$. This effluent also contains a large number of microorganisms including pathogenic character. This amount of pollution will undoubtedly harm the environment. Moreover, in addition to suspended matters runoff water wash toxic contaminants as well from the motorway - petroleum products (diesel fuel, gasoline, fuel oil), chlorides, lead and other heavy metals.

According to Russian regulations runoff should be collected, accumulated and cleaned. Currently combined sewage system collects the drained water in the area of settlements and dilutes it with domestic sewage. Separate sewer systems typically provide for storage tanks and rarely for the purification of industrial and storm water $[2,3,4]$.

Treatment of waste water must include the removal of coarse mineral impurities, sedimentation and filtration. The type and size of structures depends on the composition and quantity of the incoming sewage, as well as the treatment requirements.

In the process of sewage treatment three main types of waste are formed requiring collection, disposal and recycling:

1. the sludge from the deposition of suspended solids containing oil products, heavy metals and other contaminants;

2. the oil sludge (a mixture of water and oil) collected from the surface of the flotation plant and septic tanks;

3. waste of used filter materials.

Thus, based on the findings presented, it is clear that the design and reconstruction of the infrastructure of the industrial cities should consider the volume and quality characteristics of surface runoff, depending on the season.

In this case, the collection, accumulation of meltwater and storm water accompanies irregular regime and the changing composition of the impurities. This can be considered applying a more modern approach of the systems of collection and drainage runoff, treatment methods, technological schemes of clearing and recycling of produced liquid and solid waste. For example, the new waste water treatment plants and batch reactors, that are equipped with automatic controllers of all processes, can be used for problem solving.

Currently, treatment plants receiving surface runoff in Europe are produced by Belarusian plant water purification equipment UE "Polymer construction" and the company "Beltehagroplast"; Lithuanian company Traidenis, Finnish firm "Vavin Labko" specializes in the manufacture of water treatment facilities for industrial oily waste - EuroPEK modules; French company offers oil- and water- separation plant. 


\section{Problem}

Urban runoff is formed from melted snow, rain and a part of water allocated to industrial sites, car washes, gas stations, transport companies, roads and residential areas of the city. For example, oil products and petroleum are some of the main types of contaminants, which are present in runoff in dissolved, emulsified and colloidal forms as well as in the form of droplets and films.

Average oil content in the soils of the city of Tyumen (Russia) is $6.5 \mathrm{mg} / \mathrm{kg}$ [6].

This is less than the level adopted for the background in Russia (informally and roughly below $500 \mathrm{mg} / \mathrm{kg}$ ) and abroad and in particular in the Netherlands, the first signal level being there $50 \mathrm{mg} / \mathrm{kg}$. The urban areas with the different levels of anthropogenic impacts are presented in Figure 1. The highest concentrations of oil products were found in samples taken from the field of petrol stations, garages and railway depot [5].

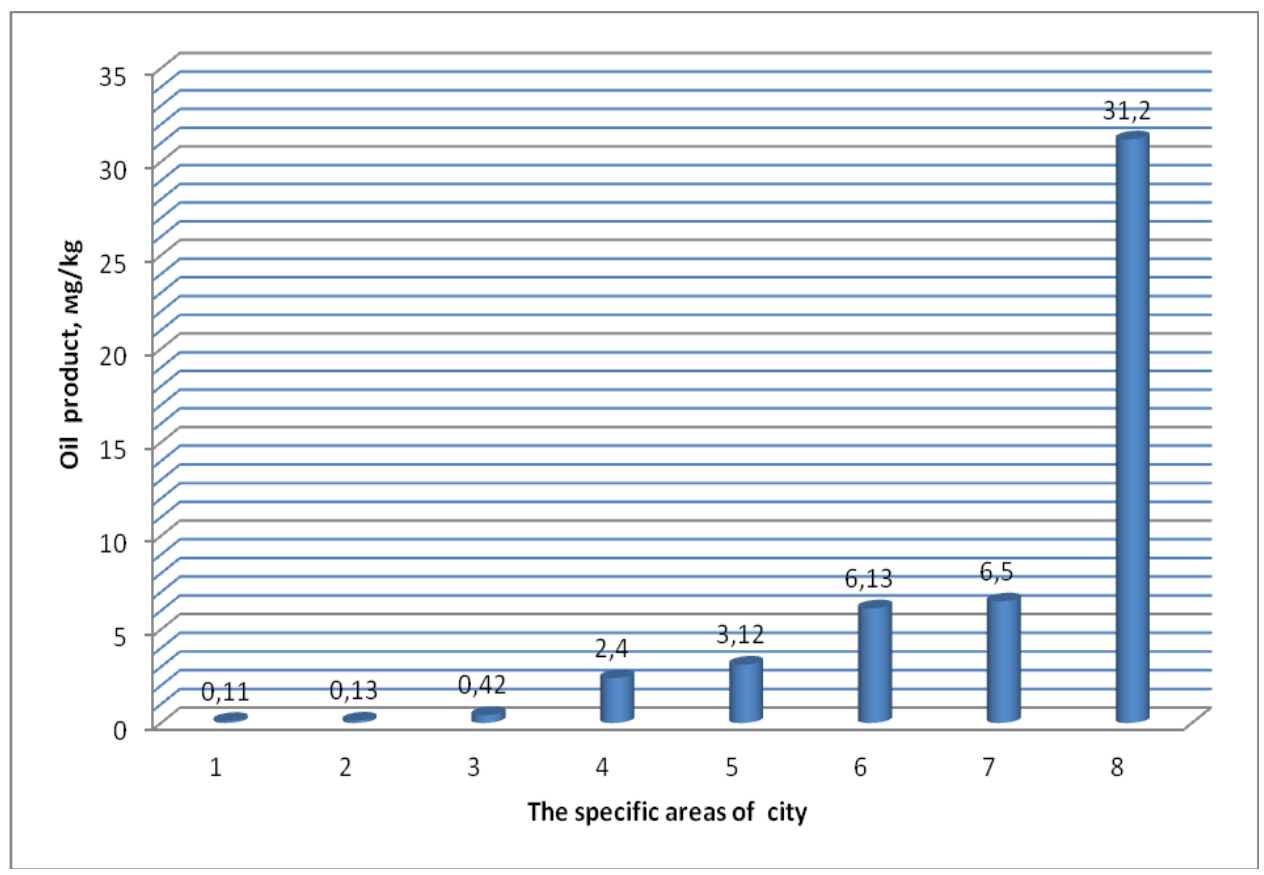

Fig. 1. The content of oil products in Tyumen (Russia), lands: 1 - suburban area of Airport, 2 Central Park of Culture and Recreation, 3 - the central area of the city, 4 - near central crossroad, 5 Railway Depot, 6 - garages, 7 - the city as a whole (city level), 8 - filling stations.

It should be noted at this point that MPC for petroleum products has not been established for the soil in the Russian Federation.

These standards should be developed for a specific area for a specific type of soil, based on the analysis of the data set on the impact of oil on the different components of ecosystems and human health.

In accordance with gradation developed by Y. Pikovsky for the background, the oil concentration of 100 to $500 \mathrm{mg} / \mathrm{kg}$ is taken for increased background.

In accordance with Annex 8 to the "Methodology of calculating the amount of damage caused by cluttering, pollution and land degradation in Moscow", approved by order of the mayor of Moscow, the permissible oil content in the soil, is $300 \mathrm{mg} / \mathrm{kg}$.

In accordance with the letter of the RF Ministry of Natural Resources number 04-25 dated December 27, 1993 and in accordance with "Guidelines for the identification of degraded and contaminated land", developed by the Office of the Russian Ministry of 
Natural Resources conservation of soil and land resources in 1994, the content of petroleum products from 1000 to $2000 \mathrm{mg} / \mathrm{kg}$ soil contamination level is considered to be low and above $5000 \mathrm{mg} / \mathrm{kg}$ it is considered to be very high.

Oil product content in the whole city soils is 6 times greater than in the background soils. There are samples taken in the vicinity of the railway station, garages (20-50 times greater than in the background soils) and around the petrol stations (283 times greater than in the background soils).

According to the results of laboratory researches the oil products are represented by the following two varieties:

- Waste oil and fuel oil that was oxidized or can be oxidized; this type of contamination is the most common, found in $76 \%$ of cases and it is characterized by low concentrations of $0.1-7.5 \mathrm{mg} / \mathrm{kg}$.

- Waste kerosene or diesel fuel; the concentrations of these substances is much higher than those of the first group, reaching up to $90 \mathrm{mg} / \mathrm{kg}$.

It is obvious that the level of human impact on the soil of urban areas is mainly due to road transport. Diffuse sources that deliver pollutants to water bodies from whole areas regards not only agricultural and forestry activities but the building up of large infrastructures and urban development.

Toxic chemicals or heavy metals in the water from industrial sources, and urban runoff, may cause many kinds of environmental problems amongst this bioaccumulation in food crops [3]. Research in these fields has to find proper treatment methods and monitoring techniques and schemes to prevent the occurrence of these problems.

Because of placing filling stations, railway station and tank farms in urban areas the oil concentration has increased even to $300 \mathrm{~g} / \mathrm{kg}$ on a few sites. The reason for this is regular accidental pollution accompanied by fuel leaks $[6,7]$.

As melt water is formed in winter, its pollution content and their impacts can also be investigated in these periods.

The pollution content of melt water is mainly can mainly be investigated formed in the winter. Snow cover, having a high sorption capacity, captures during a snowfall a significant portion of the pollutants from the atmosphere and keeps it on the ground. If this happens in the city or industrial center, the extrapolating concentration of certain types of pollution becomes rather high. Snow cover also accumulates dust fallen between snowfall periods.

With the onset of the warm period a part of the contaminants dissolves in the runoff water. Impurities which do not react with water, remain deposited on the surface of the soil. With streams one part of pollution is carried to natural lowlands, water bodies, while another part lingers in the upper layers of the soil and contaminates groundwater [20].

At present, the missing treatment of melt and storm water and the accumulation of deriving sediments are the most acute water quality management problem of the big cities. The annual rainfall in a large industrial centre is tens of thousands of tons, and its utilization is an intractable problem.

Storm water runoff from industrial sites contain a set of solid particles, generally of mineral origin (unlike domestic wastewater sludge). The volume of moisture is within 95$98 \%$, resulting hydrated granular material forms consisting of sand with petroleum content of $1-5 \%$. This precipitate also contains suspended solids, heavy metals and organic chlorides and other substances.

The average content of toxic contaminants in the sludge treatment facilities trucking companies is shown in Table 1. The highest concentration falls on petroleum products (more than $30 \mathrm{~g} / \mathrm{kg}$ ); lead leads among other metals $(140 \mathrm{mg} / \mathrm{kg}$ ); toxins such as chromium, mercury and arsenic don't allow to utilize these types of waste [6]. 
Table 1. The toxic contaminants of surface wastewater sludge.

\begin{tabular}{|c|c|}
\hline Types of pollution & $\begin{array}{c}\text { Dry matter content, } \\
\mathbf{~ m g} / \mathbf{~ k g}\end{array}$ \\
\hline oil products & 30200 \\
\hline zinc & 146.00 \\
\hline lead & 140.00 \\
\hline copper & 92.00 \\
\hline nickel & 14.90 \\
\hline chromium (mobile) & 3.70 \\
\hline cadmium & 1.10 \\
\hline mercury & 0.25 \\
\hline arsenic & 0.02 \\
\hline benzopyrene & 0.003 \\
\hline
\end{tabular}

There are some results of two series of measurements carried out in 2008, in Hungary with the aim of estimating the traffic-related heavy metal $(\mathrm{Cu}, \mathrm{Zn}, \mathrm{Pb}$ and others $)$ emissions appearing in runoff loads. Based on the metal concentrations found in runoff samples, distinct $\mathrm{Cu} / \mathrm{Zn}$ ratios are identified for urban and motorway traffic. The second method used runoff water samples during rain. The relation of the metals remained stable during one rain event [1]. The problem of effective wastewater treatment and economical utilization of sewage sludge is urgent for industrial centers. Existent popular methods, used nowadays in the world, have a range of disadvantages and are not always effective. As a result, areas occupied by wastes, increase every year. Utilization of such wastes as fertilizers is generally impossible because of high risk of infection and existence of toxic substances. In connection with this, the method of sediment treatment of urban sewage by SHF radiation is worth considering, as it not only intensifies the processes of wastewater and sludge treatment but also disinfects the product [9-20]. Considering these aspects it may be reasonable to investigate the usefulness of the method of SHF radiation as a sewage sludge treatment process.

\section{Description of studies}

Research in determination of polluted runoff water and its microwave treatment hereinafter SHF - along with studying of snow cover forming meltwater were carried out at the Industrial University of Tyumen, Russia, in the "Water supply and sanitation" department. The study of snow cover. One of the research areas of snow cover is the embankment of the river, which is located in the central part of the city of Tyumen (Russia). Conditions of sampling are: the cold autumn-winter season with the duration of 152-158 days, which lasts from late October to mid-March. During this period the average drop of snow is $60-70 \mathrm{~cm}$ in the solid form. As an indication of the intensity of snow pollution a coefficient determined by the ratio of the concentration in the liquid phase to the maximum permissible concentration (hereinafter MAC) of pollutants in water bodies was accepted.

Three places and twelve spots have been identified for the selection of the snow samples (Table 2). These points are situated perpendicular to the flow of the river. Scheme of sampling spots is shown in Figure 4. The snow was selected over the entire depth of the 
snow cover, and then it was melted at room temperature.

Table 2. Description of characteristic features of the spots.

\begin{tabular}{|c|c|c|}
\hline Alignment & Spot & Description of characteristic features of the spots \\
\hline \multirow[t]{4}{*}{1} & 1.1 & The spot at a distance of 10 meters from the river \\
\hline & 1.2 & The spot the river at a distance of 20 meters from the river \\
\hline & 1.3 & The spot is on the sidelines of the roadway near the river \\
\hline & 1.4 & $\begin{array}{l}\text { The spot is on the sidelines of the roadway near the residential } \\
\text { areas }\end{array}$ \\
\hline \multirow[t]{5}{*}{2} & 2.1 & The spot is adjacent to the pedestrian area near the river \\
\hline & 2.2 & The spot is adjacent to the pedestrian area near the roadway \\
\hline & 2.3 & The spot is on the sidelines of the roadway (the main road) \\
\hline & 2.4 & The spot in the park at a distance of 10 meters from the roadway \\
\hline & 2.5 & The spot in the park at a distance of 20 meters from the roadway \\
\hline \multirow[t]{3}{*}{3} & 3.1 & The spot is adjacent to the pedestrian area near the river \\
\hline & 3.2 & The spot is adjacent to the pedestrian area near the roadway \\
\hline & 3.3 & The spot is on the sidelines of the roadway (secondary highway) \\
\hline
\end{tabular}

For qualitative and quantitative analysis of the contamination of the snow cover the following chemical composition parameters were selected: suspended matter, chemical oxygen demand (hereinafter COD), oil products, cations (ammonium, potassium, sodium, magnesium, strontium, calcium, total iron) and anions (chlorine, sulfates, nitrates, fluorine, and phosphates). In carrying out laboratory tests the following methods were used: photometric, fluorometric, gravimetric, capillary electrophoresis, which are generally used in the analysis of natural water quality. According to the results of the chemical analysis of the liquid phase of snow samples a few indicators at each alignment proved to exceed the maximum permissible concentrations laid down in Russia. The main indicators exceeding the maximum permissible concentrations are: strontium, total iron, ammonium ion, COD, oil products and suspended mattes. Concentrations of indicators such as potassium, sodium, magnesium, calcium, chlorides, sulfates, nitrates, do not exceed the maximum permissible concentration in all samples. Qualitative and quantitative - rate of exceedance expressed in time - evaluations of the pollution intensity of snow cover in the twelve cross-sections are shown in Figure 2, 3 and 4.

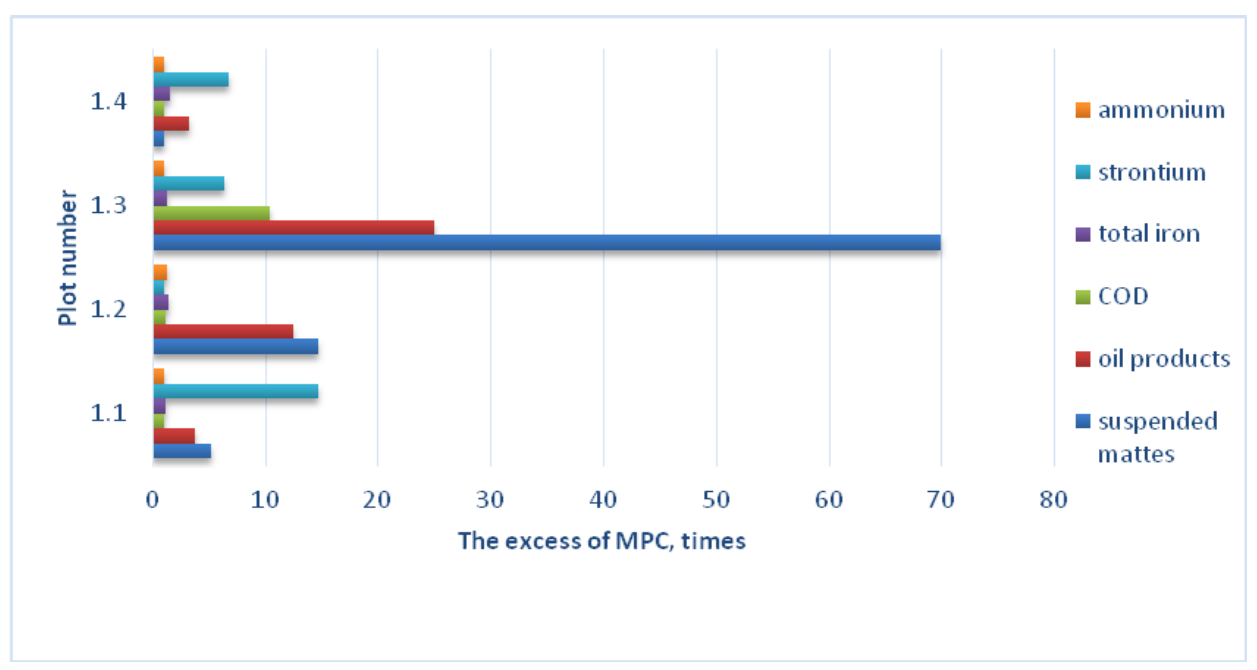

Fig. 2. Qualitative and quantitative evaluations of the pollution: spots 1.1-1.4. 


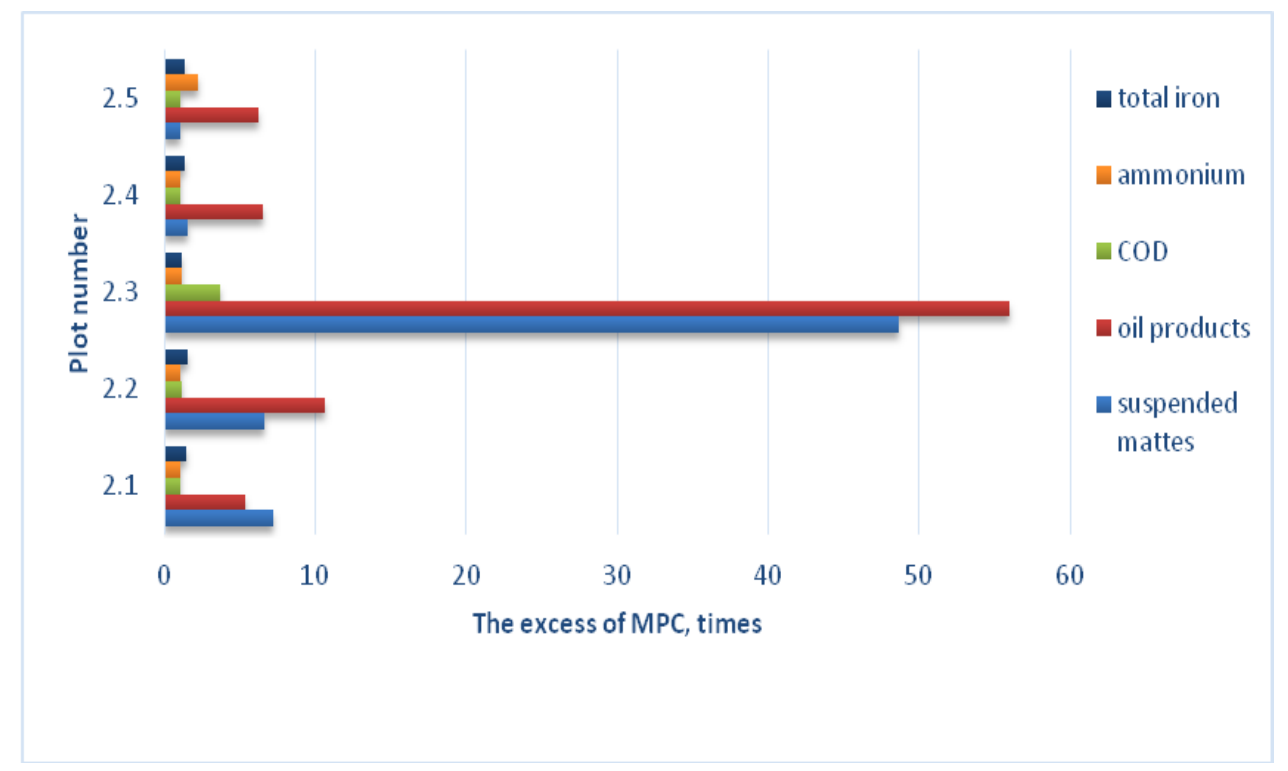

Fig. 3. Qualitative and quantitative evaluations of the pollution: spots 2.1-2.5.

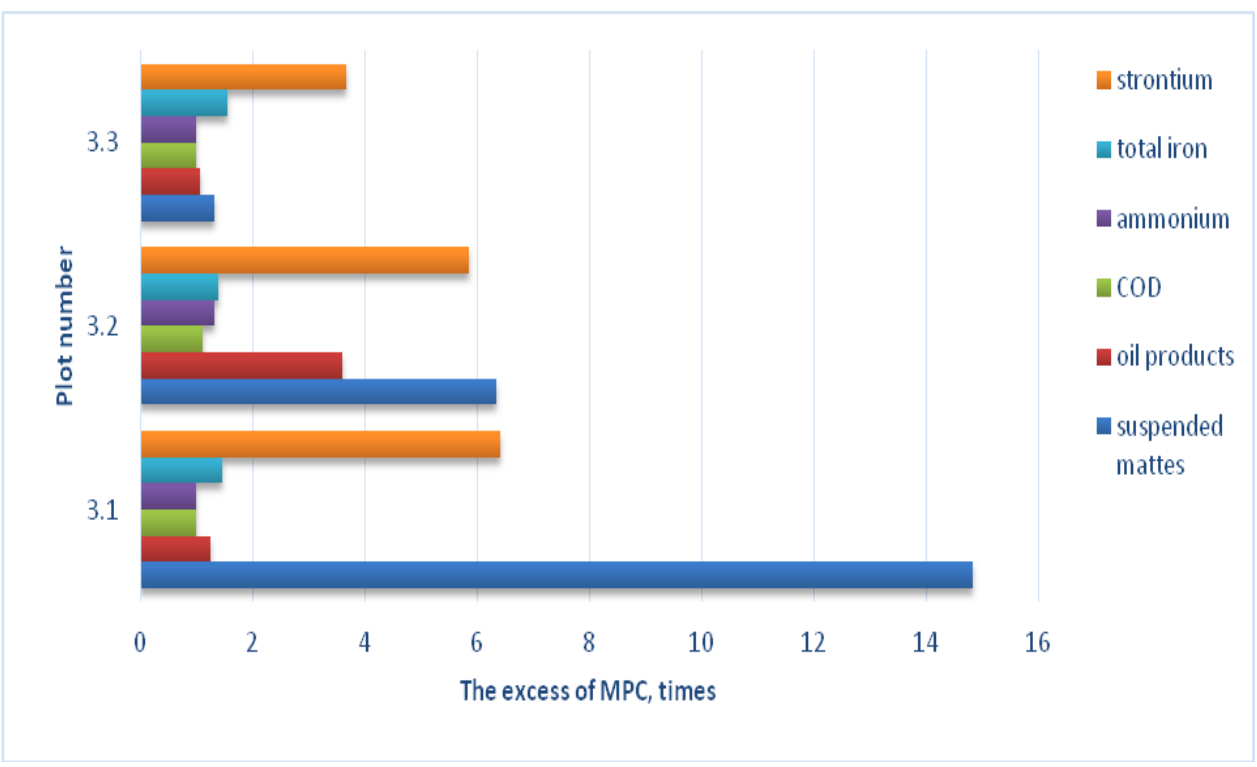

Fig. 4. Qualitative and quantitative evaluations of the pollution: spots 3.1-3.3.

According to the research, the most polluted areas of snow cover are located near areas with heavy traffic and pedestrian traffic.

Microwave electromagnetic treatment. At Industrial University of Tyumen on the chair "Water supply and sanitation" test investigations of SHF-radiation influence on the quality of wastewater and sludge from urban surfaces were carried out. The initial data on the runoff water quality and resulting new concentrations after treatment on the plant "Flow EM-1" are shown in the Table 3. The quality of processed effluents changed significantly.

It is found that the SHF-treatment of wastewater sludge intensifies the transition of arsenic, nickel, mercury, chromium in water after precipitation. Increase was observed in 
the content of heavy metal impurities in the water and, consequently, the impurities of heavy metals $(\mathrm{Cu}, \mathrm{Zn}, \mathrm{Pb})$ in these sediments are reduced by $15-30 \%$.

Table 3. The change of quality of runoff water during treatment on the plant "Flow EM-1".

\begin{tabular}{|c|c|c|}
\hline Indices & $\begin{array}{c}\text { Concentrations before } \\
\text { treatment, } \mathrm{mg} / \mathrm{dm}^{3}\end{array}$ & $\begin{array}{c}\text { Concentrations after } \\
\text { treatment, } \mathbf{m g} / \mathbf{d m}^{3}\end{array}$ \\
\hline Suspended matters & 690 & 614 \\
\hline COD & 313 & 125 \\
\hline Ammonium -ion & 1.1 & 0.8 \\
\hline Oil products & 2.8 & 1.4 \\
\hline Strontium & 5.8 & 4.6 \\
\hline Total iron & 2.1 & 1.7 \\
\hline
\end{tabular}

SHF positively influences the degree and speed of compression of sediments, thus the volume of sediments sample decreases to $30-40 \%$. This method also improves sediment quality as follows: the time of capillary suction of sediments reduces by 1.2 times; specific resistance of filtration significantly decreases from $37.5 \cdot 10^{10} \mathrm{~g} / \mathrm{cm}^{3}$ to $6.93 \cdot 10^{10} \mathrm{~g} / \mathrm{cm}^{3}$; humidity reduces to $3-4 \%$; ash content increases to $5-7 \%$.

\section{Conclusion}

Thus, the actual problem of the collection, storage and disposal of runoff water in industrial cities can be solved in several ways:

1. Creation of an effective water collection and drainage system reusing a portion of water volume for irrigation of urban green areas after proper treatment.

2. Control of quality and quantity measurement of storm water, and then application of necessary treatment.

3. Determination of urban locations with the highest concentrations of contaminants

4. That affect the quality of snowmelt and rainwater.

5. Adoption of new and more efficient technologies for the treatment of runoff water and for disposing of the produced sediments.

\section{References}

1. P. Budai, A. Clement, Transportation Research 16(3), 244-250 (2011)

2. M. Molokov, V. Shifrin, Ochistka povernoctnogo stoka $s$ territoriy gorodov I promyishlennyih ploshchadok (Stroyizdat, Moscov, 1987)

3. M. Garnier, D. M. Harper, L. Blaskovicova, G. Hancz, G. A. Janauer, Zs. Jolánkai, E. Lanz, A.Lo Porto, M. Mándoki, B. Pataki, J.L. Rahuel, C. Stoate, E. Tóth, G. Jolánkai, V.J. Robinson, Springer Environmental Management, 274-278 (2015) DOI 10.1007/s00267-015-0544-7 56

4. S.G. Nitstkaya, V.S. Speranskiy, Formirovanie povernoctnogo stoka (Izdatelskiy stentr YuUrGU, Chelyabinsk, 2009)

5. V.M. Ropot, www.ecologylife.ru/ekologiya-goroda/issledovanie-poverhnostnogostoka-s-territoriy-gorodov.html

6. A.N. Guseynov, Ecologiya goroda Tyumen (Tyumen, Slovo, 2001) 
7. V.V. Ivanov, A.V. Kochurov, V.C. Yusfin, H.M. Mystafin, A.N. Kondrashov, V.I. Voronov, Vodosnabzhenie 9, 23-26 (1999)

8. S.A. Dovgan, Ekologiya i promyishlennost Rossii 5, 28-30 (2012)

9. Voprosy teorii i praktiki magnitnoy obrabotki vody $i$ vodnykh system (Moscow, 1971)

10. V.I. Klassen, Omagnichivaniye vodnykh system (Khimiya, Moscow, 1978)

11. F. Krauford, Waves 3, 527 (1976)

12. V. I. Minenko, Tekhnika, 165 (1970)

13. P.S. Stukalov, E.V. Vasilyev, N.A. Glebov, Magnitnaya obrabotka vody (Sudostroyeniye, Leningrad, 1969)

14. V.I. Klassen, Doklady Akademii nauk SSSR 190(6), 1391-1392 (1970)

15. V.I. Klassen, U.Z. Zinoviev, Kolloidniy zhurnal 5, 758-759 (1967)

16. E.I. Vialkova, M.V. Zemlyanova, A.V. Pesheva, Materials Science Forum 871, 223233 (2016)

17. E.I. Vialkova, M.V. Zemlyanova, A.V. Pesheva, Ecology \& Safety Journal of International Scientific Publications 10, 121-129 (2016)

18. M.V. Zemlyanova, E.I. Vialkova, Vodnyye i ekologicheskiye problemy Sibiri, 144-150 (2014)

19. M.V. Zemlyanova, E.I. Vialkova, Ekologiya i promyshlennost' Rossii 6, 47-49 (2015)

20. M.V. Zemlyanova, Avtoreferat dissertatsii na soiskaniye uchenoy stepeni kandidata tekhnicheskikh nauk (2015)

21. T.V. Garmanova, N.C. Larina, Vestnik Tyumenskogo gosudarstvennogo universiteta 7, 55-62 (2012) 